\title{
Synthesis of dimethyl carbonate from oxidative carbonylation of methanol catalyzed by $\left[\mathrm{Cu}(\text { phen })(\mathrm{OAc})_{2}\right]_{2}\left(\mu-\mathrm{H}_{2} \mathrm{O}\right)$
}

\author{
Zhikang Sun ${ }^{1, a}$, Xingxing $\mathrm{Hu}^{2, \mathrm{~b}}$, Liming Huang ${ }^{3, \mathrm{c}}$, Peng Dong ${ }^{4, \mathrm{~d}}$, Wuqiang \\ Wen ${ }^{5, \mathrm{e}}$ and Zhiping $\mathrm{Du}^{6, \mathrm{f} *}$
}

(Key Laboratory for Green Chemical Process of Ministry of Education, Hubei Key Laboratory of Novel Chemical Reactor and Green Chemical Technology, Wuhan Institute of Technology, Wuhan, Hubei, 430073, People's Republic of China)

azhikangsun@yeah.net, b1229365569@qq.com, chuanglm@163.com, ddongpeng@126.com, e239362392@qq.com, dzpxyhry@163.com

Key words: Dimethyl carbonate; $\mathrm{Cu}$ coordination; Methanol; Oxidative carbonylation

Abstract. $\left[\mathrm{Cu}(\text { phen })(\mathrm{OAc})_{2}\right]_{2}\left(\mu-\mathrm{H}_{2} \mathrm{O}\right)$ (phen $=1,10$-phenanthroline) was characterized by Fourier Transform Infrared Spectrometer and Thermogravimetric analysis, and its catalytic performances were investigated in the oxidative carbonylation of methanol to dimethyl carbonate. The results showed that $\left[\mathrm{Cu}(\mathrm{phen})(\mathrm{OAc})_{2}\right]_{2}\left(\mu-\mathrm{H}_{2} \mathrm{O}\right)$ exhibited high thermal stability and catalytic properties. Turnover number of dimethyl carbonate could reach to $33.0 \mathrm{~mol}_{\mathrm{DMC}} \cdot \mathrm{mol}_{\mathrm{Cu}}{ }^{-1}$ under the conditions of reaction temperature of $120^{\circ} \mathrm{C}$, total pressure of $4.0 \mathrm{MPa}$, ratio of partial pressure of $\mathrm{CO}$ to $\mathrm{O}_{2}$ of 19 : 1 (below the explosion limit of $\mathrm{CO}$ ) and concentration of catalyst in methanol of $0.014 \mathrm{~mol} \cdot \mathrm{L}^{-1}$. When the complex was reused, the loss of $\mathrm{CH}_{3} \mathrm{COO}^{-}$resulted in the break of its bridge coordination, and the catalytic activity was lowered.

\section{Introduction}

Dimethy carbonate (DMC) has been drawing wide attention as an environment friendly building block for versatile chemical applications. DMC can also be used potentially as a fuel additive to replace methyl tert-butyl ether (MTBE)[1].

The main routes for the synthesis of DMC include phosgene method, transesterification, oxidative carbonylation of methanol, and direct carbonylation of methanol with $\mathrm{CO}_{2}$ [2]. The oxidative carbonylation of methanol with $\mathrm{CO}$ and $\mathrm{O}_{2}$ is the most perspective route, in which $\mathrm{CuCl}$ has been proven to be an efficient catalyst. But this system suffers from some disadvantages, such as low solubility in methanol and corrosive effect on metallic vessels due to the existence of $\mathrm{Cl}^{-}$. In order to overcome above drawbacks, the organic ligand containing $\mathrm{N}, \mathrm{P}$ or $\mathrm{O}$ is used, or $\mathrm{CuCl}$ is loaded on the surface of the carrier to reduce the corrosion of $\mathrm{Cl}^{-}$. However, the corrosion cannot be solved fundamentally due to the existence of $\mathrm{Cl}^{-}$. Meanwhile, after added the ligand, the amount and structure of the $\mathrm{Cu}$ coordination compound, which is in-stiu synthesized from $\mathrm{CuCl}$ and ligand, cannot be determined, so it is difficult to understand the essence of the catalytic reaction. Recently, we found that $\mathrm{Cu}$ (phen) $\mathrm{Cl}_{2}$ showed the higher activity than the mixture of $\mathrm{CuCl}_{2}$ and phen (phen $=$ 1,10-phenanthroline)[3].

In order to overcome the drawbacks caused by $\mathrm{Cl}^{-}$, the $\mathrm{Cu}$ coordination catalyst, $\left[\mathrm{Cu}(\text { phen })(\mathrm{OAc})_{2}\right]_{2}\left(\mu-\mathrm{H}_{2} \mathrm{O}\right)$, was synthesized with $\mathrm{Cu}(\mathrm{OAc})_{2}$ used to replace $\mathrm{CuCl}$, and was characterized by Thermogravimetric analysis. Its catalytic performances were also investigated in the oxidative carbonylation of methanol to dimethyl carbonate in this paper.

\section{Experimental}

Chemical reagents. All reagents were purchased from local manufactures and used without further purification. $\left[\mathrm{Cu}(\mathrm{phen})(\mathrm{OAc})_{2}\right]_{2}\left(\mu-\mathrm{H}_{2} \mathrm{O}\right)$ was synthesized on the basis of the literature[4].

Characterization of $\left[\mathrm{Cu}(\text { phen })(\mathrm{OAc})_{2}\right]_{2}\left(\mu-\mathrm{H}_{2} \mathrm{O}\right)$. Thermogravimetric analysis (TGA) was measured on a TGA Q50 analyzer under nitrogen at a heating rate of $10^{\circ} \mathrm{C} \cdot \mathrm{min}^{-1}$ from room temperature to $900^{\circ} \mathrm{C}$. FT-IR spectra were recorded on a Nicolet 6700 FT-IR spectrophotometer with $\mathrm{KBr}$ pellets in the region of $400-4000 \mathrm{~cm}^{-1}$. 
Activity evaluation of $\left[\mathrm{Cu} \text { (phen) }(\mathrm{OAc})_{2}\right]_{2}\left(\mu-\mathrm{H}_{2} \mathrm{O}\right)$. The oxidative carbonylation of methanol with $\mathrm{CO}$ and $\mathrm{O}_{2}$ was carried out in a $250 \mathrm{~mL}$ stainless steel autoclave equipped with an adjustable speed stirrer. $40 \mathrm{~mL}$ of methanol and $0.014 \mathrm{~mol} \cdot \mathrm{L}^{-1}$ of the catalyst were loaded into the autoclave. The autoclave was purged three times with $\mathrm{O}_{2}$, and then pressurized to $4.0 \mathrm{MPa}$ with $\mathrm{CO}$ and $\mathrm{O}_{2}\left(P_{\mathrm{CO}} / P_{\mathrm{O} 2}\right.$ $=19: 1)$ at room temperature. The system was heated to $120^{\circ} \mathrm{Cand}$ kept for $4 \mathrm{~h}$. After the reaction, the reactor was cooled down to room temperature. The liquid product was analyzed by a shimadzu GC-2014 equipped with a Rtx-50 capillary column and a flame ionization detector. The flow rate of $\mathrm{N}_{2}$ carrier gas was $30 \mathrm{~mL} / \mathrm{min}$, and the temperature of the capillary column was $60{ }^{\circ} \mathrm{C}$. The temperatures of the injector and the detector were $250{ }^{\circ} \mathrm{C}$ and $300^{\circ} \mathrm{C}$, respectively.

\section{Results and Discussion}

Thermogravimetric analysis of $\left[\mathrm{Cu}(\text { phen })(\mathrm{OAc})_{2}\right]_{2}\left(\mu-\mathrm{H}_{2} \mathrm{O}\right)$. As is shown in Fig. 1, the weight loss of $2.7 \%$ in the range of $115-159^{\circ} \mathrm{C}$ is close to the $2.4 \%$ weight content of $\mathrm{H}_{2} \mathrm{O}$ in $\left[\mathrm{Cu}(\text { phen })(\mathrm{OAc})_{2}\right]_{2}\left(\mu-\mathrm{H}_{2} \mathrm{O}\right)$, so it is ascribed to the remove of crystal water. When the temperature is above $200^{\circ} \mathrm{C}$, the weight loss appears successively at $200-240^{\circ} \mathrm{Cand} 240-300^{\circ} \mathrm{C}$. These are attributed to the decomposition of phen or $\mathrm{AcO}^{-}$. The results show that $\left[\mathrm{Cu}(\mathrm{phen})(\mathrm{OAc})_{2}\right]_{2}\left(\mu-\mathrm{H}_{2} \mathrm{O}\right)$ is stable below $200^{\circ} \mathrm{C}$, and can be used as the catalyst in the oxidative carbonylation of methanol because the reaction temperature is usually below $160^{\circ} \mathrm{C}$.

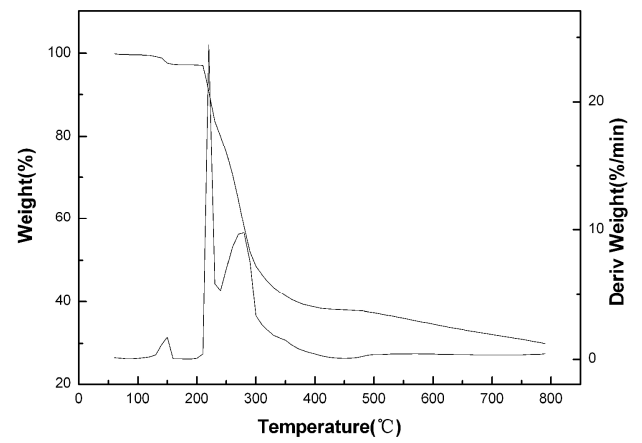

Fig. 1 TG/DTG patterns of $\left[\mathrm{Cu}(\text { phen })(\mathrm{OAc})_{2}\right]_{2}\left(\mu-\mathrm{H}_{2} \mathrm{O}\right)$

Catalytic performances. As is shown in Table 1, Turnover number (TON) was $7.4 \mathrm{~mol}_{\mathrm{DMC}} \cdot \mathrm{mol}_{\mathrm{Cu}}{ }^{-1}$ over $\mathrm{CuCl}$, and the selectivity of DMC was close to $100 \%$. However, metallic vessels are seriously corroded due to the existence of $\mathrm{Cl}^{-}$, and the activity of $\mathrm{CuCl}$ needs to be improved further. As a result, it is very urgent to develop a free-chloride catalyst with the high activity. When $\mathrm{Cu}(\mathrm{OAc})_{2}$ was used as the catalyst to replace $\mathrm{CuCl}$, TON slightly decreased, but the selectivity of DMC sharply declined to $84.7 \%$, and the byproducts of dimethoxymethane (DMM) and methyl acetate (MA) were up to $4.3 \%$ and $11.0 \%$, respectively. With the addition of phen, the selectivity of DMM and MA was reduced to $1.0 \%$ and $2.7 \%$, while TON and the selectivity of DMC increased to $25.3 \mathrm{~mol}_{\mathrm{DMC}} \cdot \mathrm{mol}_{\mathrm{Cu}}{ }^{-1}$ and $96.3 \%$, respectively. The result might arise from the formation of the $\sigma-\pi$ coordination bond between phen and $\mathrm{Cu}(\mathrm{II})$, which can improve the catalytic activity of $\mathrm{Cu}(\mathrm{OAc})_{2}$. When the complex $\left[\mathrm{Cu} \text { (phen) }(\mathrm{OAc})_{2}\right]_{2}\left(\mu-\mathrm{H}_{2} \mathrm{O}\right)$ was used as the catalyst, the selectivity of DMC, DMM and MA was nearly equal to that over the mixture of $\mathrm{Cu}(\mathrm{OAc})_{2}$ and phen. This shows that they have the same active centers. Combined with Fig. 1, $\left[\mathrm{Cu}(\text { phen })(\mathrm{OAc})_{2}\right]_{2}\left(\mu-\mathrm{H}_{2} \mathrm{O}\right)$ can be dehydrated into $\mathrm{Cu}$ (phen)(OAc) $)_{2}$ at $120^{\circ} \mathrm{C}$, so the active centers should be $\mathrm{Cu}($ phen $)(\mathrm{OAc})_{2}$. TON arrived to 33.0 $\operatorname{mol}_{\mathrm{DMC}} \cdot \mathrm{mol}_{\mathrm{Cu}}{ }^{-1}$ on $\left[\mathrm{Cu}(\mathrm{phen})(\mathrm{OAc})_{2}\right]_{2}\left(\mu-\mathrm{H}_{2} \mathrm{O}\right)$, being higher than $25.3 \mathrm{~mol}_{\mathrm{DMC}} \cdot \mathrm{mol}_{\mathrm{Cu}}{ }^{-1}$ on the mixture catalyst. The result suggests that $\mathrm{Cu}(\mathrm{OAc})_{2}$ and phen cannot be transferred completely into $\mathrm{Cu}$ (phen) $(\mathrm{OAc})_{2}$ by the in-situ reaction in the oxidative carbonylation of methanol. In addition, the activity of $\left[\mathrm{Cu}(\mathrm{phen})(\mathrm{OAc})_{2}\right]_{2}\left(\mu-\mathrm{H}_{2} \mathrm{O}\right)$ was close to that of $\mathrm{Cu}(\mathrm{phen}) \mathrm{Cl}_{2}$. This demonstrates that the chlorine ion is not essential, and can be replaced with the acetate ion. So the effect of reaction conditions on the oxidative carbonylation was investigated in detail with $\left[\mathrm{Cu}(\text { phen })(\mathrm{OAc})_{2}\right]_{2}\left(\mu-\mathrm{H}_{2} \mathrm{O}\right)$ used as the catalyst. 
Table 1 Effect of different catalysts on oxidative carbonylation of methanol

\begin{tabular}{ccccc}
\hline Catalysts & $\mathrm{S}_{\mathrm{DMC}}(\%)$ & $\mathrm{S}_{\mathrm{DMM}}(\%)$ & $\mathrm{S}_{\mathrm{MA}}(\%)$ & ${ }^{\mathrm{a}} \mathrm{TON} / \mathrm{mol}_{\mathrm{DMC}} \cdot \mathrm{mol}_{\mathrm{Cu}}{ }^{-1}$ \\
\hline $\mathrm{CuCl}$ & $>99.9$ & 0 & & 7.4 \\
$\mathrm{Cu}(\mathrm{OAc})_{2}$ & 84.7 & 4.3 & 11.0 & 4.8 \\
${ }^{\mathrm{b}} \mathrm{Cu}(\mathrm{OAc})_{2}+$ phen & 96.3 & 1.0 & 2.7 & 25.3 \\
{$\left[\mathrm{Cu}(\text { phen })(\mathrm{OAc})_{2}\right]_{2}\left(\mu-\mathrm{H}_{2} \mathrm{O}\right)$} & 96.1 & 1.7 & 2.2 & 33.0 \\
$\mathrm{Cu}($ phen $) \mathrm{Cl}_{2}$ & 98.3 & 1.7 & & 39.0
\end{tabular}

Reaction conditions: $V_{\mathrm{MeOH}} 40 \mathrm{~mL}, C_{\mathrm{Cu}}=0.014 \mathrm{~mol} \cdot \mathrm{L}^{-1}, 120^{\circ} \mathrm{C}, 4 \mathrm{MPa}, P_{\mathrm{CO}}: P_{\mathrm{O} 2}=19: 1,4 \mathrm{~h}$.

${ }^{\mathrm{a}}$ Turnover number $(\mathrm{TON})=\mathrm{n}(\mathrm{DMC}) / \mathrm{n}$ (copper ions).

${ }^{\mathrm{b}}$ The equimolar mixture of phen and $\mathrm{Cu}(\mathrm{OAc})_{2}$ was stirred for $20 \mathrm{~min}$ before the reaction started.

Effect of reaction conditions on the oxidative carbonylation. The effect of reaction temperature and reaction time on the carbonylation was tested. The results are summarized in Fig. 2 and Fig. 3. As exhibited in Fig. 2, TON increased gradually with the rise of the temperature, and arrived to the peak value of $33.0 \mathrm{~mol}_{\mathrm{DMC}} \cdot \mathrm{mol}_{\mathrm{Cu}}{ }^{-1}$ at $120^{\circ} \mathrm{C}$. Above $120{ }^{\circ} \mathrm{C}$, the synthesis of DMC was inhibited because the carbonylation was exothermic. On the contrary, the hydrolysis rate of DMC and the generation rate of DMM and MA were accelerated. Thus, TON and the selectivity of DMC were gradually reduced. In summary, the optimal reaction temperature was $120^{\circ} \mathrm{C}$.

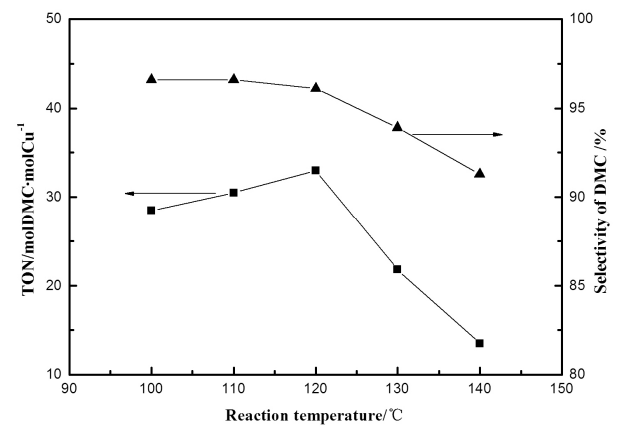

Fig.2 Effect of the reaction temperature on the carbonylation

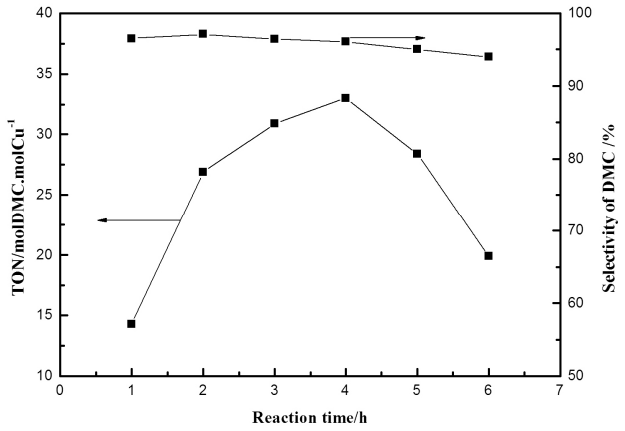

Fig.3 Effect of the reaction time on the synthesis of DMC

As listed in Fig. 3, TON was only $14.3 \mathrm{~mol}_{\mathrm{DMC}} \cdot \mathrm{mol}_{\mathrm{Cu}}{ }^{-1}$ within $1 \mathrm{~h}$. With the reaction time enhanced to $4 \mathrm{~h}$, TON increased to $33.0 \mathrm{~mol}_{\mathrm{DMC}} \cdot \mathrm{mol}_{\mathrm{Cu}}{ }^{-1}$. Above $4 \mathrm{~h}$, TON and the DMC selectivity decreased because the side reactions were accelerated. So the optimal reaction time was $4 \mathrm{~h}$.

Reuse of $\left[\mathrm{Cu}(\text { phen })(\mathrm{OAc})_{2}\right]_{2}\left(\mu-\mathrm{H}_{2} \mathrm{O}\right)$. As presented in Table 2, TON and the selectivity of DMC were reduced when the catalyst was used for the second time, especially, TON was only 16.7 $\mathrm{mol}_{\mathrm{DMC}} \cdot \mathrm{mol}_{\mathrm{Cu}}{ }^{-1}$. After the catalyst was reused for two times, TON and the selectivity of DMC remained approximately unchanged.

Table 2 Reuse of $\left[\mathrm{Cu}(\text { phen })(\mathrm{OAc})_{2}\right]_{2}\left(\mu-\mathrm{H}_{2} \mathrm{O}\right)$

\begin{tabular}{ccccc}
\hline Reuse number & $\mathrm{S}_{\mathrm{DMC}}(\%)$ & $\mathrm{S}_{\mathrm{DMM}}(\%)$ & $\mathrm{S}_{\mathrm{MA}}(\%)$ & $\mathrm{TON} / \mathrm{mol}_{\mathrm{DMC}} \cdot \mathrm{mol}_{\mathrm{Cu}}{ }^{-1}$ \\
\hline 1 & 96.1 & 1.7 & 2.2 & 33.0 \\
2 & 90.3 & 3.4 & 6.7 & 16.7 \\
3 & 96.2 & 3.0 & 0.8 & 15.4 \\
4 & 97.6 & 2.4 & - & 15.1 \\
\hline
\end{tabular}

Reaction conditions: $V_{\mathrm{MeOH}} 40 \mathrm{~mL}, C_{\mathrm{Cu}}=0.014 \mathrm{~mol} \cdot \mathrm{L}^{-1}, 120^{\circ} \mathrm{C}, 4 \mathrm{MPa}, P_{\mathrm{CO}}: P_{\mathrm{O} 2}=19: 1,4 \mathrm{~h}$.

FT-IR spectra of the fresh catalyst were compared with that of the used catalyst. As shown in Fig. 4 , there are the skeleton vibration absorption of phen at $1518 \mathrm{~cm}^{-1}$ and the stretching vibration absorption of the $\mathrm{Cu}-\mathrm{N}$ bond at $428 \mathrm{~cm}^{-1}$ in two catalysts. This shows that the $\mathrm{Cu}-\mathrm{N}$ bond is stable. In the fresh catalyst, $v_{a s}\left(-\mathrm{COO}^{-}\right)$between 1610 and $1560 \mathrm{~cm}^{-1}$ overlaps the skeleton vibration absorption of phen, so the strong and wide absorption appears at $1586 \mathrm{~cm}^{-1}$. After the reaction, the overlapped peak is divided into $v(\mathrm{C}=\mathrm{N})$ at $1632 \mathrm{~cm}^{-1}, v(\mathrm{C}=\mathrm{C})$ at $1604 \mathrm{~cm}^{-1}$ and $v_{a s}\left(-\mathrm{COO}^{-}\right)$at $1578 \mathrm{~cm}^{-1}$. By referring back to Table 1, MA was detected in the reaction liquid. At the same time, $\mathrm{Cu}^{2+}$ as a Lewis acid can catalyze the esterification reaction of $\mathrm{CH}_{3} \mathrm{COO}^{-}$and methanol. Thereby, the changes of FT-IR spectra might stem from the loss of $\mathrm{CH}_{3} \mathrm{COO}^{-}$caused by the esterification. 


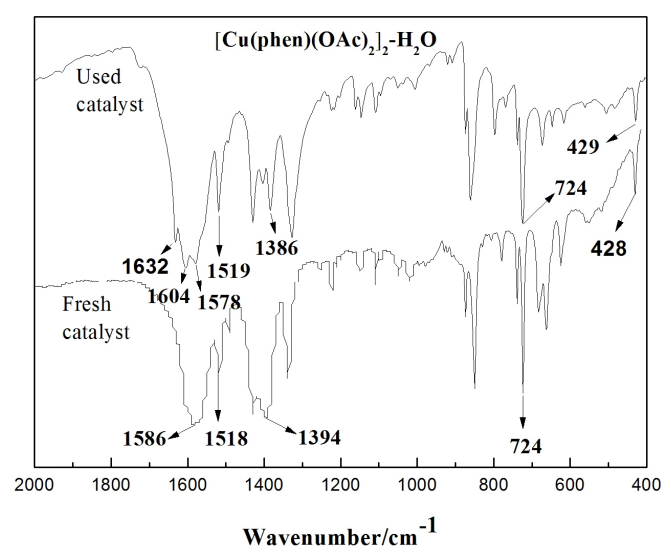

Fig. 4 FT-IR spectra of the complex

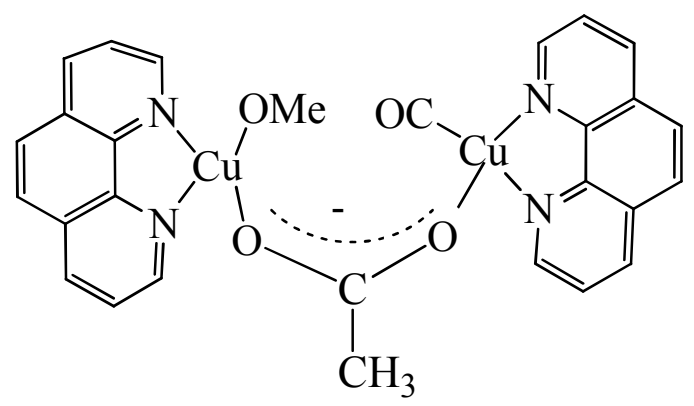

Fig. 5 The bridging effect of acetate moiety

The preliminary study has showed that a $\mathrm{Cu}(\mathrm{I}, \mathrm{II})$-Cl-bridged cluster[5], which stems from a cupric methoxy derivative and a cuprous carboxyl species, is a key to synthesize DMC. When $\left[\mathrm{Cu}(\text { phen })(\mathrm{OAc})_{2}\right]_{2}\left(\mu-\mathrm{H}_{2} \mathrm{O}\right)$ catalyzed the oxidative carbonylation, the acetate anion as a bidentate ligand could replace $\mathrm{Cl}^{-}$to play a bridging role (Fig. 5). When the catalyst was reused, the bridging effect was gradually weakened due to the loss of $\mathrm{CH}_{3} \mathrm{COO}^{-}$, thus the TON value decreased. With the total loss of $\mathrm{CH}_{3} \mathrm{COO}^{-}$, the activity of the catalyst tended to the stabilization, so TON and the selectivity of DMC remained approximately unchanged.

\section{Conclusions}

$\left[\mathrm{Cu}(\text { phen })(\mathrm{OAc})_{2}\right]_{2}\left(\mu-\mathrm{H}_{2} \mathrm{O}\right)$ was prepared with phen and $\mathrm{Cu}(\mathrm{OAc})_{2}$ as the materials, and showed the high thermal stable. When it was used as the catalyst in the oxidative carbonylation of methanol to DMC, TON was up to $33.0 \mathrm{~mol}_{\mathrm{DMC}} \cdot \mathrm{mol}_{\mathrm{Cu}}{ }^{-1}$ with the $96.1 \%$ selectivity under the reaction conditions of the catalyst concentration of $0.014 \mathrm{~mol} \cdot \mathrm{L}^{-1}$, reaction temperature of $120{ }^{\circ} \mathrm{C}$, pressure of $4.0 \mathrm{MPa}$ and pressure ratio of $P_{C O}$ to $P_{O 2}$ of $19: 1$. With its reuse, the activity was lowered due to the loss of $\mathrm{CH}_{3} \mathrm{COO}^{-}$resulting in the break of the formation of the mixed valence $\mathrm{Cu}$ center through the bridge coordination of $\mathrm{CH}_{3} \mathrm{COO}^{-}$.

\section{Acknowledgements}

This work was supported by the Program of National Natural Science Foundation of China (21276201).

\section{References}

[1] Shengping Wang, Wei Li, Yuanyuan Dong, Yujun Zhao, Xinbin Ma, Chin. Chem. Lett. 3365 (2015) $1-5$.

[2] Dinghua Liu, Jian He, Linbing Sun, Xiaoqin Liu, Qin Zhong, J. TaiWan Inst. Chem. Eng. 42 (2011) 616-621.

[3] ZhiPing Du, Bing Zhou, Liming Huang, Chen Huang, Yuanxin Wu, Chin. J. Catal. 33 (2012) 736-742.

[4] M. Barquin, M.J.G. Garmendiaa, L. Larrinaga, E. Pinillab, and M.R. Torresb, Z. Anorg. Allg. Chem. 631 (2005) 2151-2155.

[5] Zhiping Du, Lihua Xiong, Zhikong Lin, Xuli Li, Yigang Ding, Yuanxin Wu, Chin. J. Chem. Eng. 22 (2014) 1117-1121. 